\title{
RESEARCH
}

Open Access

\section{Effects of gene mutation and disease progression on representative neural circuits in familial Alzheimer's disease}

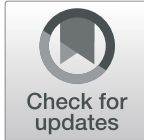

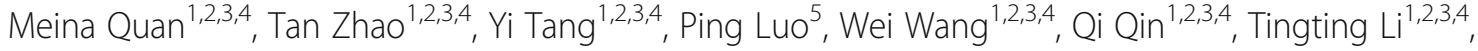 \\ Qigeng Wang ${ }^{1,2,3,4}$, Jiliang Fang ${ }^{5}$ and Jianping Jia ${ }^{1,2,34^{*}}$ (D)
}

\begin{abstract}
Background: Although structural and functional changes of the striatum and hippocampus are present in familial Alzheimer's disease, little is known about the effects of specific gene mutation or disease progression on their related neural circuits. This study was to evaluate the effects of known pathogenic gene mutation and disease progression on the striatum- and hippocampus-related neural circuits, including frontostriatal and hippocampusposterior cingulate cortex (PCC) pathways.
\end{abstract}

Methods: A total of 102 healthy mutation non-carriers, 40 presymptomatic mutation carriers (PMC), and 30 symptomatic mutation carriers (SMC) of amyloid precursor protein (APP), presenilin 1 (PS1), or presenilin 2 gene, with T1 structural MRI, diffusion tensor imaging, and resting-state functional MRI were included. Representative neural circuits and their key nodes were obtained, including bilateral caudate-rostral middle frontal gyrus (rMFG), putamen-rMFG, and hippocampus-PCC. Volumes, diffusion indices, and functional connectivity of circuits were compared between groups and correlated with neuropsychological and clinical measures.

Results: In PMC, APP gene mutation carriers showed impaired diffusion indices of caudate-rMFG and putamenrMFG circuits; PS1 gene mutation carriers showed increased fiber numbers of putamen-rMFG circuit. SMC showed increased diffusivity of the left hippocampus-PCC circuit and volume reduction of all regions as compared with PMC. Imaging measures especially axial diffusivity of the representative circuits were correlated with neuropsychological measures.

Conclusions: APP and PS1 gene mutations affect frontostriatal circuits in a different manner in familial Alzheimer's disease; disease progression primarily affects the structure of hippocampus-PCC circuit. The structural connectivity of both frontostriatal and hippocampus-PCC circuits is associated with general cognitive function. Such findings may provide further information about the imaging biomarkers for early identification and prognosis of familial Alzheimer's disease, and pave the way for early diagnosis, gene- or circuit-targeted treatment, and even prevention.

Keywords: Familial Alzheimer's disease, Neural circuits, Gene mutation, Diffusion tensor imaging, Resting-state functional MRI

\footnotetext{
* Correspondence: jjp@ccmu.edu.cn

${ }^{1}$ Innovation Center for Neurological Disorders and Department of Neurology,

Xuanwu Hospital, Capital Medical University, National Clinical Research

Center for Geriatric Diseases, Beijing, People's Republic of China

${ }^{2}$ Beijing Key Laboratory of Geriatric Cognitive Disorders, Beijing, People's

Republic of China

Full list of author information is available at the end of the article
}

(c) The Author(s). 2020 Open Access This article is distributed under the terms of the Creative Commons Attribution 4.0 International License (http://creativecommons.org/licenses/by/4.0/), which permits unrestricted use, distribution, and reproduction in any medium, provided you give appropriate credit to the original author(s) and the source, provide a link to the Creative Commons license, and indicate if changes were made. The Creative Commons Public Domain Dedication waiver (http://creativecommons.org/publicdomain/zero/1.0/) applies to the data made available in this article, unless otherwise stated. 


\section{Background}

Alzheimer's disease is the cause of $60-70 \%$ of cases of dementia, the population of which is estimated to be $40-50$ million worldwide, more than doubled from 1990 to 2016 [1]. Without disease-modifying treatment, Alzheimer's disease has become an increasing challenge to healthcare systems and economy in China [2] and internationally. Several recent clinical trials of Alzheimer's disease targeting the amyloid hypothesis especially by lowering amyloid-beta $(\mathrm{A} \beta)$ have failed, which led us to think about other therapeutic targets for Alzheimer's disease [3]. In recent years, circuit or network level treatments for $\mathrm{AD}$ have shown some promising results [4], such as deep-brain stimulation [5-7]. Following this trend, it is critical to look for circuit level imaging biomarkers that can help with early diagnosis and treatment.

Familial Alzheimer's disease (FAD) accounts for 15-25\% of total Alzheimer's disease [8], and it has presented a useful model in studying pathogenesis and trajectory of the disorder. FAD includes autosomal dominant Alzheimer's disease (ADAD), carrying known causative gene mutation including the amyloid precursor protein $(A P P)$, presenilin 1 (PS1), or presenilin 2 (PS2) that are nearly $100 \%$ certain to show sequential pre-dementia and dementia stage clinical features and thus can be diagnosed before symptoms onset. FAD also includes those carrying unknown variants in PS1/ $P S 2 / A P P$ gene or other gene mutations. Our team has recently reported $P S 1 / P S 2 / A P P$ mutations in 404 Chinese pedigrees with FAD [9]. Treatment could also be initiated at a presymptomatic stage in $\mathrm{FAD}$, which promotes the development of intervention and prevention trials $[10,11]$.

Imaging studies in FAD suggest that striatum and hippocampus are possibly the earliest involved brain regions. Amyloid positron emission tomography (PET) imaging studies in ADAD mutation carriers have shown striatal amyloid deposition before symptoms appeared [12-17], which were often greater than deposits observed in the signature regions such as medial temporal lobe and medial parietal and frontal cortices. A longitudinal imaging study of ADAD found elevated PET tracer uptake in all subcortical regions including the striatum, before the involvement of the hippocampus [18]. MRI studies confirmed the early volumetric changes of the striatum $[15,19,20]$ and hippocampus $[16,21,22]$ in FAD before symptom onset. In addition to volumetric changes, diffusion tensor imaging (DTI) confirmed finer structural changes of the striatum and hippocampus in preclinical stage of FAD relative to controls $[20,23]$. There are also a few functional MRI studies showing early functional changes of the striatum or hippocampus in preclinical FAD [24-26]. These numerous imaging findings guided us to look for striatum- and hippocampus-related neural circuits.

The striatum receives cortical input projection fibers that are part of the glutamatergic neural circuits [27].
Subregions of the striatum, especially the superior and lateral part of caudate and putamen, receive dense projection from the dorsolateral prefrontal cortex (DLPFC), which plays a critical role in cognitive function such as executive function and working memory [28-33]. On the other hand, imaging studies found a significant relationship between hippocampus activation and posterior cingulate cortex (PCC) during episodic memory encoding and recognition task in mild cognitive impairment (MCI) patients [34] and association between hypometabolism in hippocampus-PCC subnetwork and episodic memory deficits in pre-dementia stage [35]. Notably, the above cognitive function domains on which the frontostriatal and hippocampus-PCC circuits play important roles are impaired even in the preclinical stage of Alzheimer's disease [36, 37].

Up to now, little is known about the structural and functional features of frontostriatal and hippocampusPCC neural circuits during the whole disease spectrum of FAD. Furthermore, most of the above imaging findings in FAD have involved mutation carriers of various genes, while not looked at the effect of specific gene. Imaging studies have shown gene- or mutation-specific effect on brain structure [38, 39] and function [40] in Alzheimer's disease, but the gene-specific effect on the frontostriatal and hippocampus-PCC neural circuits remains uncertain.

This study was aimed at exploring the effects of specific gene mutations (primarily PS1 and APP) and disease progression on the structure and function of frontostriatal and hippocampus-PCC circuits in FAD. We hypothesize that the structure and function of these representative circuits would be impaired in the early stages of FAD and would be more damaged with disease progression. Moreover, they would be affected differently by PS1 and APP mutations.

\section{Methods \\ Participants}

All the participants were recruited from August 2014 to February 2018, as part of the ongoing Chinese Familial Alzheimer's Disease Network study (CFAN, Study ID Number: SYXWJ002; ClinicalTrials.gov Identifier: NCT03657732) at Xuanwu Hospital, which receives research referrals from across China. Participants enrolled in CFAN study were examined on the basis of neuropsychological testing, neuroimaging, genetic testing, and fluid biomarker measurements. FAD in CFAN study was defined as at least one first-degree relative in addition to the patient himself/herself within the family who had an objective cognitive decline suggestive of $\mathrm{AD}$ [8]. We included 70 subjects carrying known gene mutations for this study. Forty of these subjects were presymptomatic mutation carriers (PMC), and the rest 30 subjects were symptomatic mutation carriers (SMC). The mutations include PS1 (H163R, L282V, L392V, M270L, 
L271V, M139V, M139L, I213T, A285V, F105I, I100F, K311R, P433S, G111V, L173F, G206S), PS2 (F181I, V214L, M298T, G34S), and APP (I716T, V717I, V715M). A group of 102 healthy mutation non-carriers (control) within the FAD pedigrees who do not carry the three known gene mutations were also included. All subjects underwent neuropsychological assessments including the Mini-Mental State Examination (MMSE) and the Montreal Cognitive Assessment (MoCA) for cognitive functions, and Clinical Dementia Rating scale (CDR) for clinical symptoms. Estimated years from symptom onset (EYO) were calculated for the SMCs by subtracting the participant's age at which he/ she first developed symptoms of progressive cognitive decline from his/her current age, and for the PMC group by subtracting the mean family age at symptom onset from his/ her current age. All subjects had undergone clinical diagnosis and were aware of their mutation status. All subjects gave written informed consent according to the Declaration of Helsinki, and the study was approved by the Medical Research Ethics Committee at Xuanwu Hospital.

Additional inclusion criteria for the current study were as follows: subjects had T1, DTI and rsfMRI imaging scans from the same scanner within one scanning period, and T1 image passed quality control. Participants with any condition that might preclude completion of neuropsychological testing or MRI scanning, and with stroke, vascular disease, infarcts, hemorrhages, hydrocephalus, white matter lesions, or hyperintensities were excluded. After inclusion of subjects, further quality control was done for DTI and rsfMRI scans. The DTI quality control resulted in the exclusion of 75 scans because of incomplete coverage of the brain due to a restricted field of view, and 16 scans because of significant motion affecting the intensity of some volumes. The rsfMRI quality control resulted in the exclusion of 29 scans because of incomplete coverage of the brain due to a restricted field of view, two scans because of motion affecting the intensity of some volumes, and one scan because of missing certain number of volumes. Image exclusion steps can be found in Additional file 1: Flowchart S1.

\section{Image acquisition}

All subjects were scanned on the same 3.0-T Siemens Skyra scanner (Germany) using a 20-channel phased array head-neck coil. Whole-brain T1-weighted threedimensional magnetization-prepared rapid gradient echo (MPRAGE) scans (repetition time $=5000 \mathrm{~ms}$, echo time $=$ $2.98 \mathrm{~ms}$, inversion time $=700$ and $2500 \mathrm{~ms}$, flip angle $=4^{\circ}$, field of view $=256 \times 240 \mathrm{~mm}$, matrix $=256 \times 240$, voxel size $=1.0 \times 1.0 \times 1.0 \mathrm{~mm}$ ) were acquired. The DTI images were obtained using whole-brain 30-direction spin-echo echo planar imaging (EPI) sequence (field of view $=220 \times$ $220 \mathrm{~mm}$, matrix $=110 \times 110$, voxel size $=2.0 \times 2.0 \times 2.0$ $\mathrm{mm}, 60$ contiguous axial slices, repetition time $=8100 \mathrm{~ms}$, echo time $=90 \mathrm{~ms}$ ). The acquisition was performed axially with an anterior-to-posterior phase-encoding direction. Twelve reference volume $\left(b=0 \mathrm{~s} / \mathrm{mm}^{2}\right)$ and 90 diffusion volumes $\left(b=1000 \mathrm{~s} / \mathrm{mm}^{2}\right)$ with uniformly distributed diffusion directions were acquired. RsfMRI scans were collected using a gradient EPI sequence (repetition time $=$ $2500 \mathrm{~ms}$, echo time $=30 \mathrm{~ms}$, flip angle $=90^{\circ}$, field of view $=$ $210 \times 210 \mathrm{~mm}$, matrix $=70 \times 70,43$ axial slices, slice thickness $=3 \mathrm{~mm}$, voxel size $=3.0 \times 3.0 \times 3.0 \mathrm{~mm}$ ). Participants were required to keep their eyes closed during the resting-state scanning. Imaging data were stored in DICOM format (.dcm) and converted to nifty format (.nii) using $\mathrm{dcm} 2$ nii software for processing.

\section{$\mathrm{T} 1$ image processing and volume of gray matter ROI}

T1 images were preprocessed using fslmaths and FreeSurfer software [41] (Additional file 1), which resulted in an additional exclusion of nine T1 scans. After preprocessing, six subcortical gray matter regions of interest (ROIs) including bilateral caudate, putamen, and hippocampus were obtained for each subject; four cortical gray matter ROIs were obtained, including bilateral PCC and rostral middle frontal gyrus (rMFG), which likely represents DLPFC based on a previous study [42]. The volume (absolute volume) of each ROI for each subject was calculated from the FreeSurfer software automatically. Then the relative volume of each ROI for each subject was calculated (the percentage of ROI absolute volume in intracranial volume), so as to correct the effect of difference in brain size among subjects.

DTI processing and structural connectivity of neural circuits DTI images were preprocessed using FSL software [43, 44] (Additional file 1), which resulted in an additional exclusion of three DTI scans. After preprocessing, the DTI data were analyzed using Probtrack (probabilistic tracking) module in FSL software [43]. Specifically, the bilateral caudate, putamen, and hippocampus were set as seed ROIs separately, and bilateral rMFG and PCC were set as waypoint masks separately. At the end, six white matter tracts (fdt paths) were obtained, including bilateral caudate-rMFG tracts, putamen-rMFG tracts, and hippocampus-PCC tracts. After obtaining the fdt paths, masks for each tract were generated with the threshold of 100. Diffusion parameters including fractional anisotropy (FA), mean diffusivity (MD), axial diffusivity $(\mathrm{AxD})$, and radial diffusivity $(\mathrm{RD})$ were measured using fslstats command. Fiber numbers were obtained from the waytotal output file.

\section{RsfMRI processing and functional connectivity of neural circuits}

The data of rsfMRI were preprocessed using SPM [45] and BRANT software [46] (Additional file 1), which resulted in an additional exclusion of seven scans with excess motion (translation or rotation parameters above $1.5 \mathrm{~mm}$ or $1.5^{\circ}$ ). After preprocessing, a seed-based approach was performed 
to calculate the functional connectivity (FC) $[47,48]$. Mean rsfMRI signals were extracted from each of the ROIs separately by averaging the time course signals of all voxels within the ROI. Pearson's correlation coefficients were computed between caudate, putamen, and rMFG and between the hippocampus and PCC. The correlation coefficients ( $r$ values) of each pair of regions were transformed to $z$ values by Fisher's $Z$ transformation process to make it in accordance with Gaussian distribution [49]. Then $z$ values of each pair of regions of each individual, representing FC between two ROIs, were used for subsequent group comparisons.

\section{Statistical analyses}

All statistical analyses were performed using SPSS 22.0. For demographic data, continuous variables were compared between groups (PMC vs. Control, and SMC vs. PMC) using the independent sample $t$-test, and categorical variables were compared between groups using the chi-square test. For imaging data including relative volume of each ROI, diffusion parameters and FC of each tract, outliers (>2SD) were excluded first from each group. Then, data were compared among control, PMC, and SMC groups using UNIANOVA, controlling for age and sex. Then the PMC group was divided into PS1 group, APP group, and $P S 2$ group. Demographic data were further compared in PMC between PS1 and APP groups (PS2 group was ignored due to a small sample size). PS1 and APP mutation groups were compared with the control group using UNIANOVA, controlling for age and sex, to see the effect of specific gene mutation on structural and functional connectivity of the neural circuits. Then the SMC group was divided into $\mathrm{MCI}$ and dementia groups. Due to the limited sample size for DTI data, UNIANOVA was used to only compare ROI volume and FC among PMC (pre-MCI), $\mathrm{MCI}$, and dementia groups, controlling for age and sex, to see the effect of early and late disease progression on the neural circuits. Bonferroni correction was used to correct for multiple comparison. Finally, partial correlation analyses controlling for age, sex, and education were performed for the imaging measures that showed group differences, to see the association of them with neuropsychological and clinical measures including MMSE total score, MoCA total score, CDR global score, and EYO.

\section{Results}

\section{Subject characteristics}

Detailed demographic information are presented in Table 1. The PMC group was younger than the control group $[t(140)=-3.224, P=0.002]$ and SMC group $[t(65.2)=-$ 4.720, $P<0.001]$. The SMC group had a higher male to female ratio than the PMC group $\left(X^{2}=1.595, P=0.038\right)$. The SMC group had higher EYO than the PMC group $[t(45.4)=-7.253, P<0.001]$. The three groups were similar in education level and proportion of $A P O E \varepsilon 4$. SMC and PMC had similar proportion of the three known gene mutations. The SMC group had lower MMSE $[t(29.0)=-$ 7.973, $P<0.001]$ and MoCA $[t(32.9)=-9.392, P<0.001]$ scores than the PMC group. Furthermore, in the PMC group, the $P S 1$ and $A P P$ mutation groups were not different

Table 1 Subject demographics, neuropsychological, and clinical data

\begin{tabular}{|c|c|c|c|c|c|}
\hline & Control $(n=102)$ & PMC $(n=40)$ & SMC $(n=30)$ & $P$ value PMC vs. Control & $P$ value SMC vs. PMC \\
\hline Age (years) & $44.4(12.6)$ & $36.3(15.7)$ & $50.5(9.4)$ & $0.002^{* *}$ & $<0.001^{* * *}$ \\
\hline Sex (male/female) & $37 / 65$ & $14 / 26$ & $18 / 12$ & 0.887 & $0.038^{\#}$ \\
\hline Education (years) & $11.0(5.3)$ & $12.1(4.1)$ & $10.5(4.2)$ & 0.249 & 0.118 \\
\hline EYO (years) & N/A & $-11.6(13.2)$ & $4.1(3.1)$ & & $<0.001^{* * *}$ \\
\hline MMSE & $29.0(1.6)$ & $28.8(1.8)$ & $16.5(8.0)$ & 0.498 & $<0.001^{* * *}$ \\
\hline MoCA & $27.1(2.3)$ & $27.1(3.0)$ & $12.7(7.7)$ & 0.872 & $<0.001^{* * *}$ \\
\hline CDR & N/A & N/A & $1.3(0.8)$ & & \\
\hline \multicolumn{6}{|l|}{ Subject numbers } \\
\hline APP/PS1/PS2 & N/A & $17 / 21 / 2$ & $9 / 18 / 3$ & & 0.474 \\
\hline APOEE4 (Y/N) & $26 / 76$ & $8 / 32$ & $10 / 20$ & 0.490 & 0.207 \\
\hline T1 MRI after PP & 95 & 40 & 28 & & \\
\hline DTI after QC+PP & 45 & 24 & 9 & & \\
\hline rsfMRI after QC+PP & 84 & 30 & 19 & & \\
\hline
\end{tabular}

For continuous variables, data are shown in mean (SD), and the independent sample $t$-test was used for group comparison; for categorical variables, the chisquare test was used for group comparison. Bonferroni correction was used to correct for multiple comparison. ${ }^{\#} 0.025<P<0.05,{ }^{* *} 0.001<P<0.01,{ }^{* * *} P<0.001$ $Y / N$ the number of subjects carrying $(\mathrm{Y})$ or not carrying $(\mathrm{N}) A P O E \varepsilon 4, P P$ preprocessing, QC quality control, $P M C$ presymptomatic mutation carriers, SMC symptomatic mutation carriers, EYO estimated years from symptom onset, MMSE Mini-Mental State Examination, MoCA Montreal Cognitive Assessment, CDR Clinical Dementia Rating scale 
in age (PS1: $34.0 \pm 14.7$ years, $A P P: 35.7 \pm 15.4$ years) or EYO (PS1: $-11.1 \pm 13.4$ years, APP: $-13.2 \pm 13.7$ years).

\section{Overall group comparison of the structure and function of neural circuits}

Figure 1 shows the ROIs of a representative subject in structural space. UNIANOVA showed that there were group differences in the volume of all the ROIs (Fig. 2, $P \mathrm{~s}<0.05)$ except for the left caudate which showed a marginal difference $(F=2.604, P=0.077)$. Compared with the control group, PMC showed a trend level volume increase in the right caudate (Fig. 2b, $P=0.039$ ); SMC showed volume reduction in the bilateral putamen, hippocampus, rMFG, and PCC $\left(P_{\mathrm{s}}<0.0167\right)$. Compared with PMC, SMC showed volume reduction in all ROIs $(P \mathrm{~S}<0.0167)$ except for the left caudate which showed a trend level difference $(P=0.029)$. Figure 3 shows the white matter tracts of a representative subject in diffusion space. UNIANOVA among control, PMC, and SMC showed that there were group differences in the fiber numbers $(F=4.456, P=$ $0.015)$ of left caudate-rMFG tract; $\mathrm{MD}(F=3.510, P=$ $0.035), \operatorname{AxD}(F=3.310, P=0.042)$ and $\operatorname{RD}(F=3.930, P=$ $0.024)$ of right caudate-rMFG tract; and $\operatorname{AxD}(F=4.574$, $P=0.014$ ) of left hippocampus-PCC tract (Fig. 4).
Compared with the control group, PMC showed trend level reduced fiber numbers $(P=0.044)$ of the left caudate-rMFG tract; SMC showed significant reduced fiber numbers $(P<0.0167)$ of the left caudaterMFG tract, trend level increased MD $(P=0.020)$ and $\operatorname{AxD}(P=0.022)$, and significant increased $\mathrm{RD}$ $(P<0.0167)$ of the right caudate-rMFG tract. Compared with $\mathrm{PMC}$, SMC showed significantly increased AxD $(P<0.0167)$ of the left hippocampusPCC tract. Medial and lateral views of bilateral ROIs in standard space are shown in Additional file 1: Figure S1. UNIANOVA among control, PMC, and SMC showed a trend level group difference in $\mathrm{FC}$ of the left caudate-rMFG tract $(F=2.923, P=0.057)$. Compared with the control group, PMC showed a trend level increased FC (Fig. 4f, $P=0.024$ ).

Effects of gene mutation on the structure and function of neural circuits

In PMC, subjects were divided into PS1, APP, and PS2 mutation groups. Due to the small sample size of $P S 2$ group, we only compared the PS1 and APP groups with the control group. In the APP mutation group, there was a trend level decreased volume in the right putamen
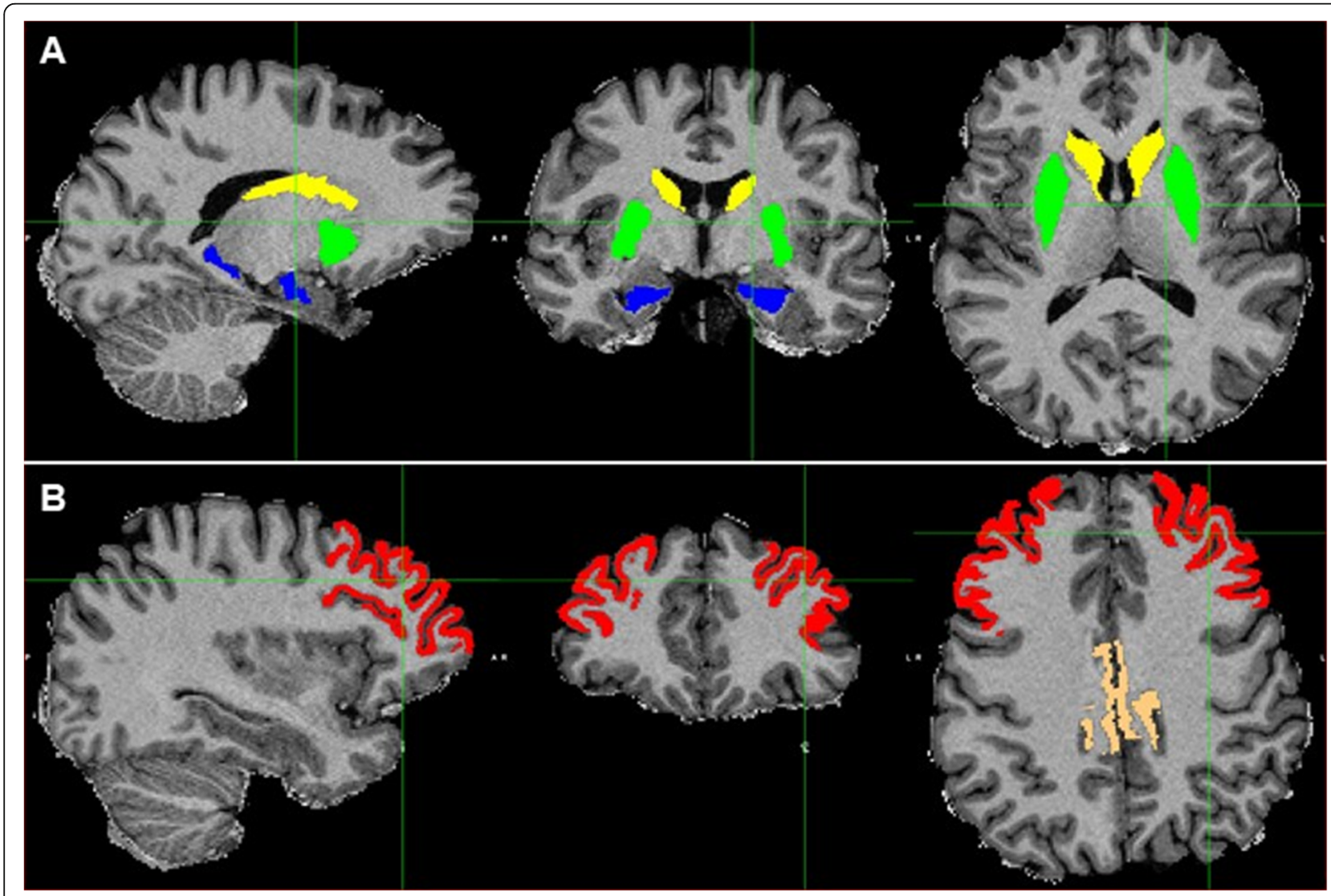

Fig. 1 The ROls of a representative subject in structural space. The subcortical ROls (a) include the bilateral caudate (yellow), putamen (green), and hippocampus (blue); the cortical ROIs (b) include rMFG (red) and PCC (brown) 


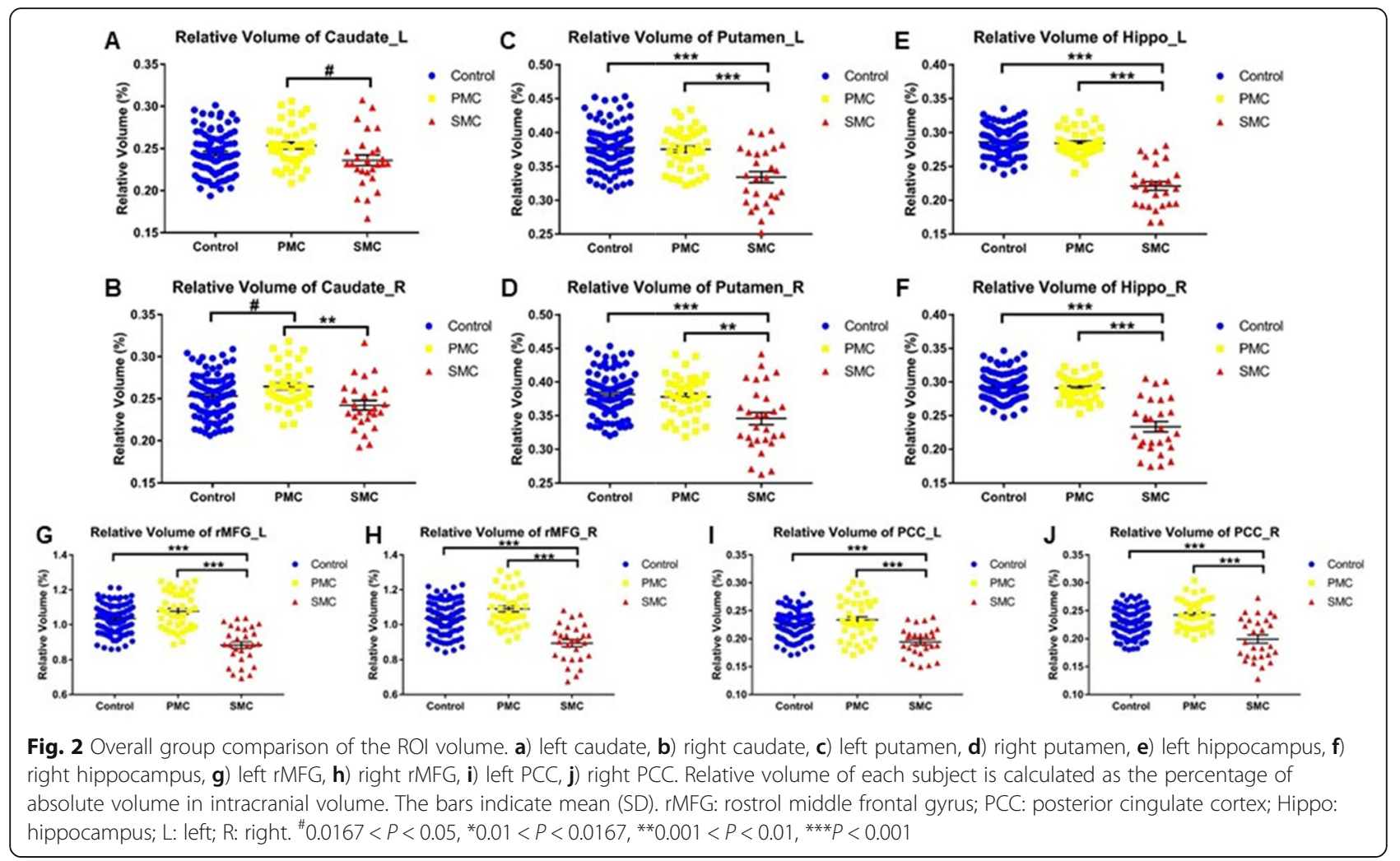

(Fig. 5a, $F=3.972, P=0.049$ ); significantly reduced fiber numbers of the left putamen-rMFG tract (Fig. 5b, $F=$ 5.630, $P<0.025)$; trend level reduced fiber numbers (Fig. 5 c, $F=4.360, P=0.042$ ), reduced FA (Fig. 5 d, $F=$ 4.134, $P=0.047$ ), and significantly increased RD (Fig. 5e, $F=7.175, P<0.025)$ of the left caudate-rMFG tract; trend level increased MD (Fig. 5f, $F=4.189, P=0.046$ ) and significantly increased RD (Fig. 5g, $F=6.488, P<$ 0.025 ) of the right caudate-rMFG tract; and trend level increased FC of the left caudate-rMFG tract (Fig. 5h, $F=4.150, P=0.045)$. The PS1 mutation group showed trend level increased fiber numbers of the left putamenrMFG tract (Fig. 5b, $F=4.789, P=0.033$ ).

\section{Effects of disease progression on the structure and function of neural circuits}

In mutation carriers, UNIANOVA showed volume reduction of bilateral hippocampus (Fig. 6e, f, $P=0.002$ for left, $P=0.016$ for right) and right rMFG (Fig. 6 h, $P=0.003$ ) in MCI stage; and volume reduction of all the ROIs in dementia stage (Fig. $6, P_{\mathrm{s}}<0.0167$ ) as compared with pre-MCI stage. Furthermore, as compared with $\mathrm{MCI}$ stage, bilateral caudate (Fig. 6a, b, $P=0.008$ for left, $P=0.009$ for right), bilateral hippocampus (Fig. 6e, f, $P=0.001$ for left, $P=0.002$ for right), and left rMFG (Fig. $6 \mathrm{~g}, P=0.001$ ) showed volume reduction in dementia stage. RsfMRI data did not show group difference in FC of any tract (figure not shown).

\section{Neuropsychological and clinical correlations of neural} circuits

Additional file 1: Figure S2 shows the results of neuropsychological and clinical correlations of the imaging measures of neural circuits that showed overall group differences. In SMC, AxD of the right caudate-rMFG tract correlated significantly negatively with MMSE $(r=-0.939, P=0.018)$ and MoCA total score $(r=-$ $0.905, P=0.035$ ), and significantly positively with CDR global score $(r=0.995, P=0.005)$; FC of the left caudate-rMFG tract correlated significantly positively with MMSE total score $(r=-0.590, P=0.034)$. In addition, there were significant correlations of relative volume in all the ROIs with MMSE, MoCA, and CDR global score (Additional file 1: Figure S3, S4 and S5), but not with EYO. Combining SMC and PMC, AxD of the left hippocampus-PCC tract correlated significantly negatively with MMSE $(r=-0.558, P=0.003)$ and MoCA total score $(r=-0.531, P=0.005)$. In PMC, RD of right caudate-rMFG tract correlated significantly positively with MMSE total score in PS1 carriers $(r=$ $0.749, P=0.020)$ but not in APP carriers $(r=0.565, P>$ 0.05 ); relative volume of right putamen correlated significantly positively with MMSE total score in PS1 carriers $(r=0.511, P=0.036)$ but not in APP carriers $(r=0.198$, $P>0.05)$. In the control group, none of the imaging measures showed significant correlation with neuropsychological or clinical measures (figure not shown). 

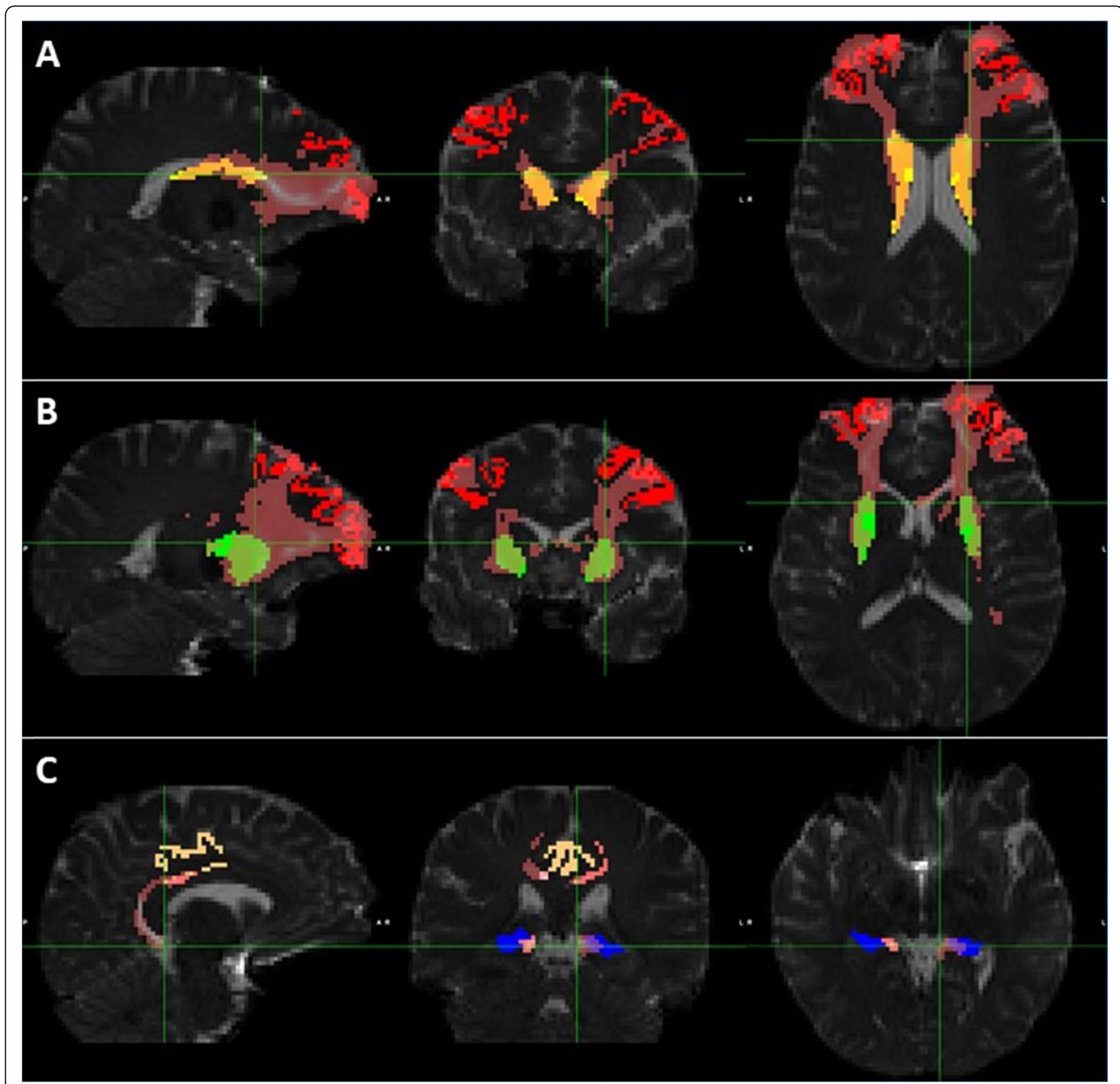

Fig. 3 The ROls and tracts of a representative subject in diffusion space. The tracts (pink) include the bilateral caudate-rMFG (a), putamen-rMFG (b), and hippocampus-PCC (c). The ROls are in the same color with those in Fig. 1

\section{Discussion}

To the best of our knowledge, this is the first study looking at the effects of different gene mutations and disease progression on the specific striatum- and hippocampusrelated neural circuits in FAD. The major findings were that $A P P$ and $P S 1$ gene mutations affected the structure and function of the frontostriatal pathway in a different manner in presymptomatic stage, where APP primarily impaired the structural connectivity; disease progression especially affected the structure of hippocampus-PCC pathway; and structural connectivity of both frontostriatal and hippocampus-PCC circuits were associated with general cognitive function in FAD. Our findings may deepen our understanding of the circuit-based imaging biomarkers of Alzheimer's disease and pave the way for early identification, prediction of prognosis, and development of gene- or circuit-targeted treatment and prevention.

For the overall group comparison, our results primarily indicate increased volume, reduced fiber numbers, and elevated function of the caudate-rMFG tract at the presymptomatic stage, while later impairment of the structure of both caudate-rMFG and hippocampus-PCC tracts. Regarding volume changes of the caudate and hippocampus in PMC of FAD, the results of previous studies were inconsistent. While 

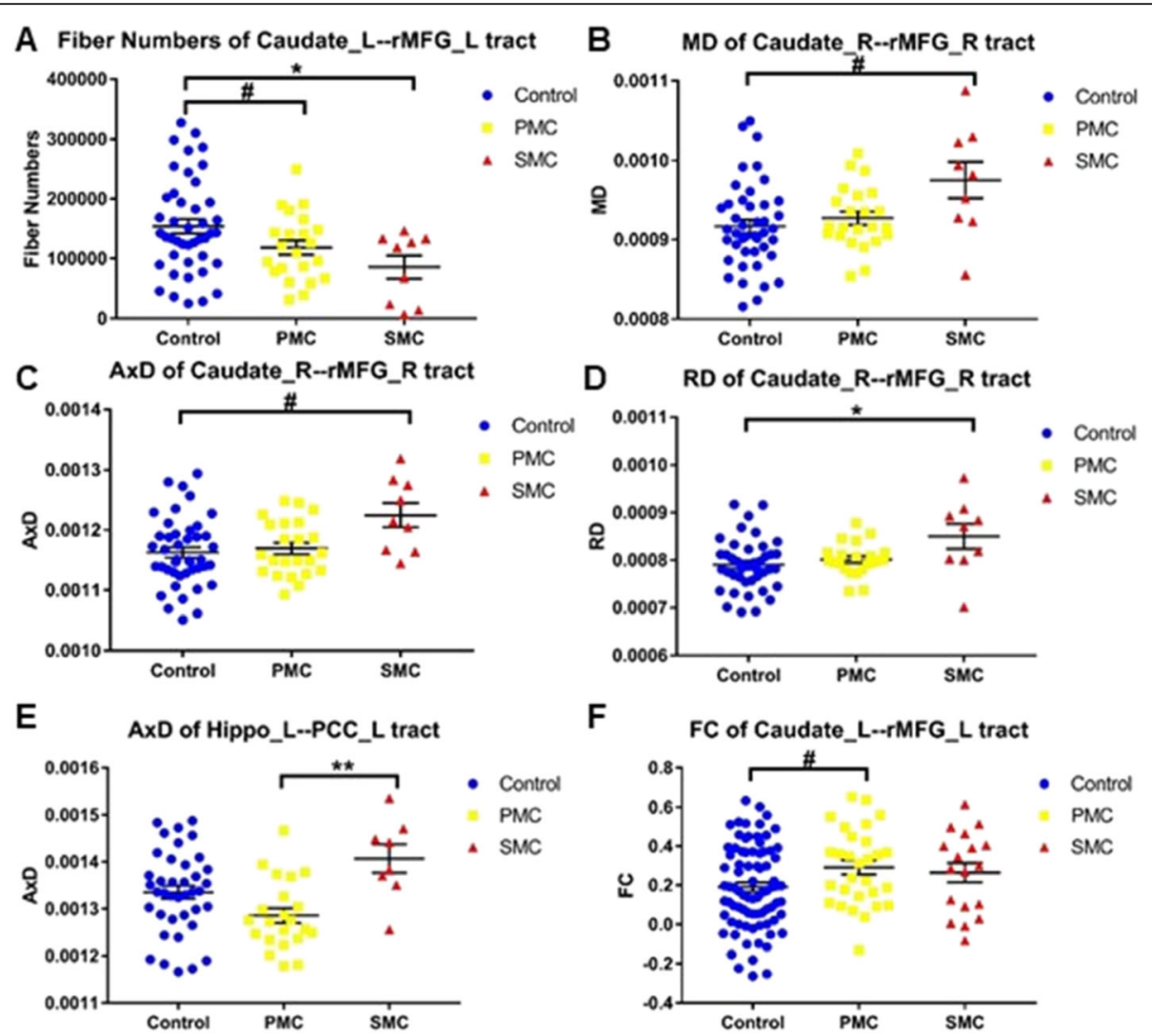

Fig. 4 Overall group comparison of the structural and functional connectivity of neural circuits. a) fiber numbers of left caudate-rMFG tract, b) MD of right caudate-rMFG tract, $\mathbf{c}$ ) AxD of right caudate-rMFG tract, d) RD of right caudate-rMFG tract, e) AxD of left hippo-PCC tract, $\mathbf{f}$ ) FC of left caudate-rMFG tract. MD: mean diffusivity; AxD: axial diffusivity; RD: radial diffusivity; FC: functional connectivity. The bars indicate mean (SD). ${ }^{\#} 0.0167<P<0.05,{ }^{*} 0.01<P<0.0167,{ }^{*} 0.001<P<0.01$

some reported volume increase of the caudate [23], some reported volume reduction of the caudate $[19,20]$ and hippocampus [16, 21, 50], and some reported no volume change of the caudate [51] or hippocampus [20, 23]. Such discrepancy might be due to the differences in subjects' demographics (such as EYO, mutations, and age), small sample sizes, or different image segmentation and statistical methods [39]. Caudate volume, like some key cortical regions, might follow an inverted U-shape nonlinear pattern over time from presymptomatic to symptomatic stages, as evidenced by longitudinal imaging studies $[15,51]$, which could be explained by initial reactive neuronal hypertrophy, neuroinflammation, and/or amyloid accumulation followed by neurodegeneration. Regarding structural connectivity changes, previous DTI studies showed a similar nonlinear pattern in tracts containing caudate or hippocampus, including increased FA and decreased diffusivity in PMC, while increased diffusivity in SMC [20, 23, 52], which might reflect earlier pathological changes such as inflammation, microglial activation/accumulation, and swelling of neurons and glia, while later impairment of white matter integrity of cellular structures [20]. Our results in both the caudate-rMFG and hippocampus-PCC tracts are consistent with such pattern though not significant in PMC. On the other hand, reduced fiber numbers of the caudate-rMFG tract in our study might reflect loss of axons or myelination [53], indicating white matter tract degeneration [54]. Regarding functional changes, our results in the caudate-rMFG tract were also consistent with an inverted U-shape nonlinear pattern though not significant in SMC, probably due to a small sample size or early in the disease progression (short EYO) in SMC. Increased connectivity may indicate high processing burden and/or noisy inefficient synaptic communication [55], as highly connected regions are particularly vulnerable to $A \beta$ deposition because of their increased synaptic activity, according to the "nodal stress" hypothesis [56-58].

For the effect of gene mutation on the structure and function of the representative neural circuits, our results indicate that $A P P$ mutation has early deleterious effect on the structural integrity of frontostriatal neural circuits, while PS1 mutation has little or even compensatory effect on it. The detrimental effects of APP mutation on frontostriatal pathway include loss of axons or myelination, reduction in white matter integrity and disruption of white matter microstructures as measured by fiber numbers [53, 54], FA [59], and MD [52], respectively. In addition, $\mathrm{AxD}$ and $\mathrm{RD}$, 

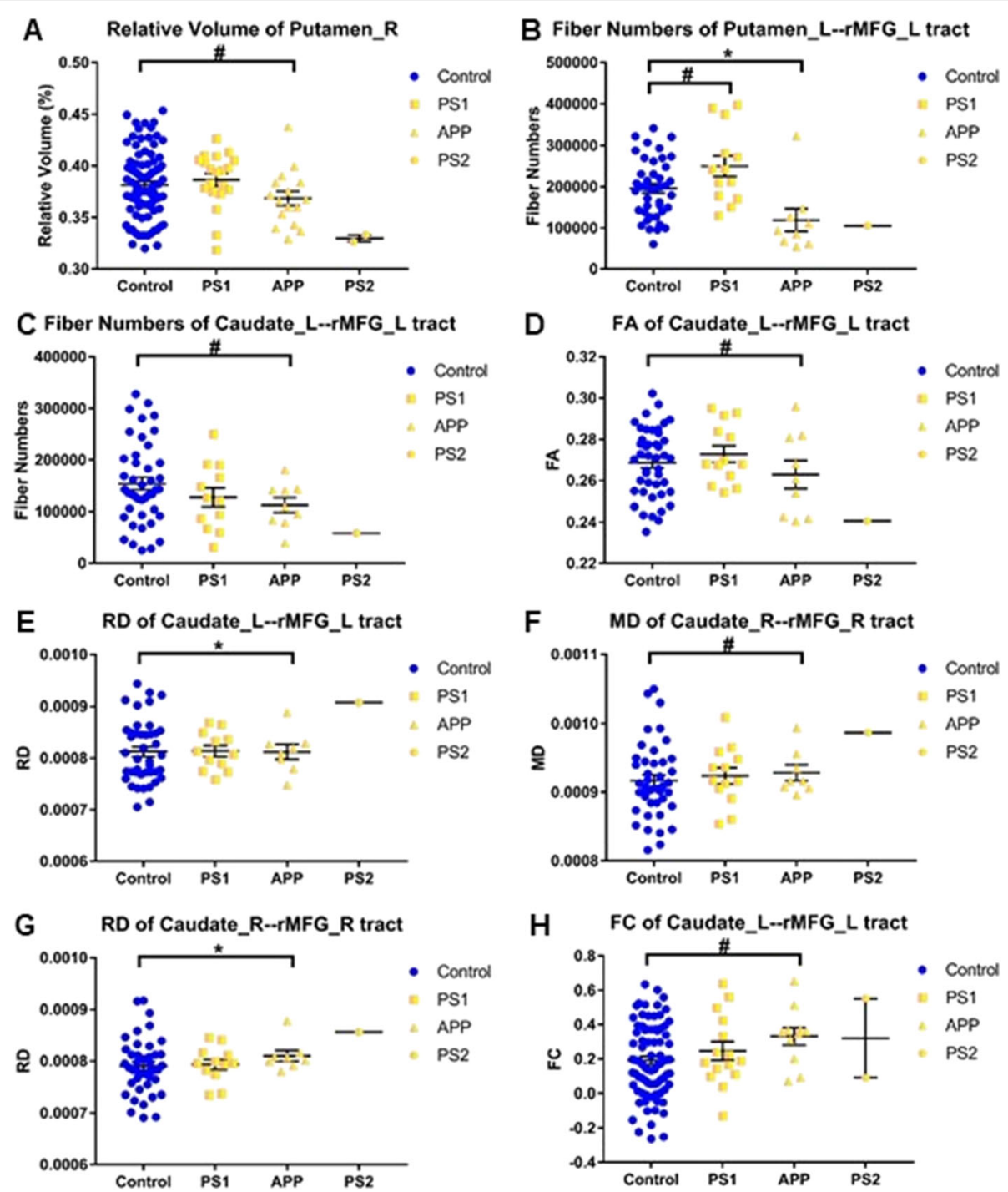

Fig. 5 Effects of gene mutation on the imaging measures of neural circuits. a) relative volume of right putamen, $\mathbf{b}$ ) fiber numbers of left putamen-rMFG tract, $\mathbf{c}$ ) fiber numbers of left caudate-rMFG tract, d) FA of left caudate-rMFG tract, e) RD of left caudate-rMFG tract, $\mathbf{f}$ ) MD of right caudate-rMFG tract, $\mathbf{g}$ ) RD of right caudate-rMFG tract, $\mathbf{h}$ ) FC of left caudate-rMFG tract. PS1 and APP mutation subjects without symptoms were compared with the control group, respectively. PS2 mutation subjects were listed for reference though not compared with the control group due to the small sample size. The bars indicate mean (SD). ${ }^{\#} 0.025<P<0.05,{ }^{*} 0.01<P<0.025$

the principal direction and perpendicular direction of the diffusion ellipsoid, have been shown to assess axonal integrity and myelin integrity, respectively [60]. Our findings indicate that $A P P$ mutation primarily affects myelin integrity while preserving axonal integrity. Furthermore, APP mutation is the primary contributor to the increased FC in the caudate-rMFG tract, which might be due to a compensatory mechanism that prevents cognitive decline, or reflect the early pathological changes. On the contrary, the little or compensatory effect of PS1 mutation on the frontostriatal circuits is increased axons or myelination in putamenrMFG tract. Neuronal hypertrophy has been shown in cognitive normal subjects with $\mathrm{AD}$ pathologies, which might be a probable reaction to $A \beta[61]$. There is evidence showing different levels of damage to the right DLPFC-right caudate-left thalamus-right DLPFC circuit in different MCI groups (reverted to normal, stable, or progressed to dementia), which indicates that FC of the frontostriatal circuit might be a potential biomarker for early detection of Alzheimer's disease [62]. Our findings of the different effects of $A P P$ and $P S 1$ mutation on this circuit expanded our understanding of this potential biomarker. Both APP and PS1 mutation can cause direct elevation of the $A \beta$ level via alterations of their encoding proteins and, as a result, affect synaptic plasticity [40,63]. They also affect other functions of their encoding proteins, such as axonal transport, lysosome 


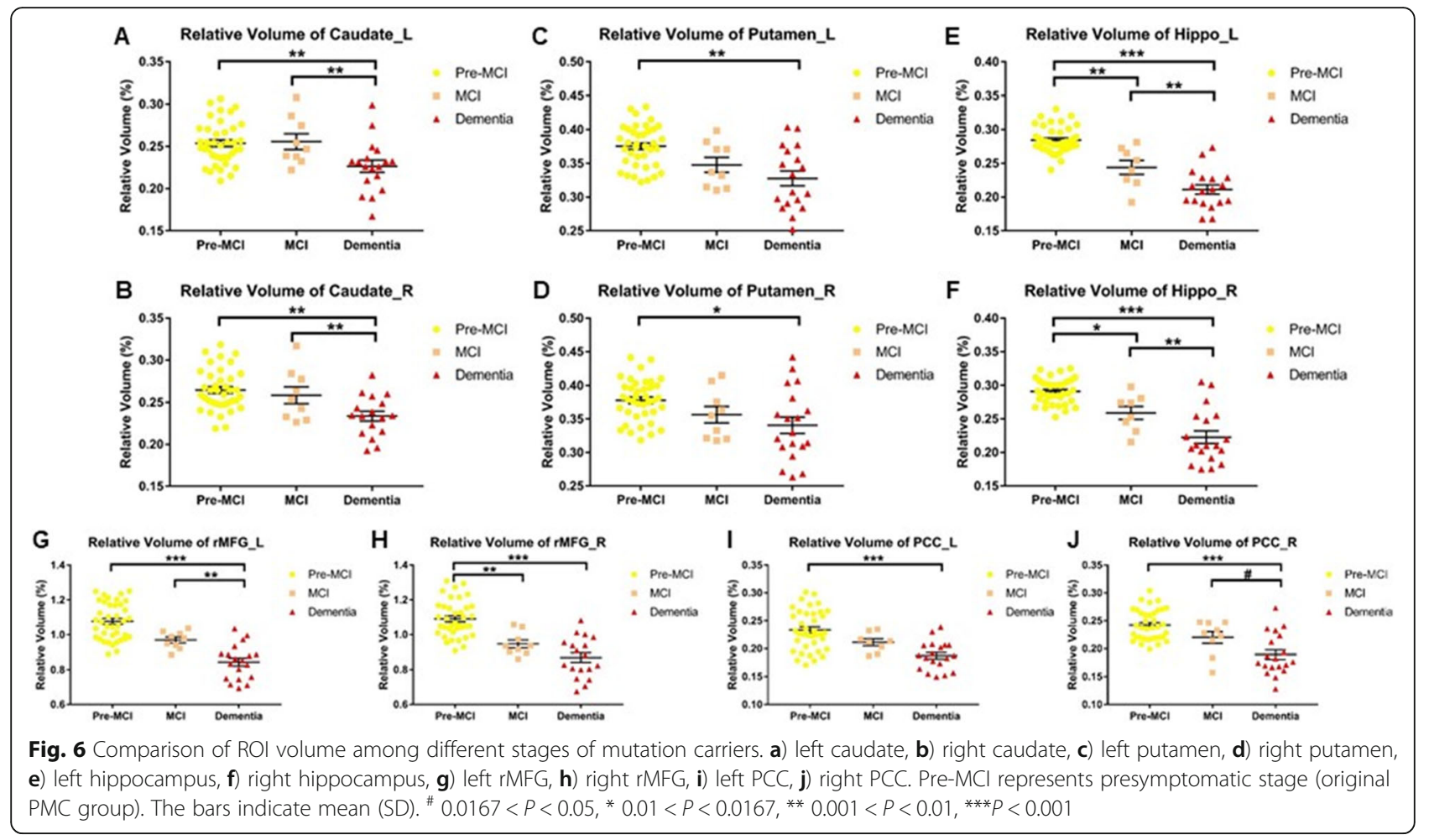

function, and autophagy [64-66], all of which can affect the properties of neural circuits. The lysosomal-autophagy defects are dependent on APP protein and not independent phenotypes due to either APP or PS1 mutation. Furthermore, PS1 mutant neurons do not have early endosome defects, in contrast with APP mutant neurons [65]. These evidence may partially explain the different effects of $A P P$ and PS1 mutation on the neural circuits in our study.

For the effect of disease progression on the representative neural circuits, our results indicate that disease progression has deleterious effect on the structure of the frontostriatal and hippocampus-PCC circuits (especially the latter), while no effect on the function of them. Imaging studies in early symptomatic stage of FAD found cortical thinning of prefrontal cortices [51] and atrophy of the hippocampus [67], which were consistent with our findings of rMFG and hippocampal atrophy in MCI stage. Imaging studies in FAD have also shown increased diffusivity of the hippocampus, cingulum, and hippocampus-cingulum tract from PMC to SMC $[20,23,52]$. A longitudinal imaging study found that increased diffusivity of the hippocampus-PCC tract predicted tau accumulation in the downstream-connected PCC and memory decline in amyloid-positive subjects [68], which further supported that the structural connectivity of the hippocampus-PCC circuit is a potential biomarker for disease progression and in line with the amyloid and tau hypothesis. Our findings of increased AxD while no change in $\mathrm{RD}$ of the hippocampus-PCC tract indicate that disease progression primarily affects axonal integrity while preserving myelin integrity. There is evidence of increased diffusivity (especially $\mathrm{AxD}$ ) of cingulum angular bundles connecting to the hippocampus in individuals with MCI and sporadic Alzheimer's disease even after controlling for hippocampal volume [69], suggesting that axonal damage of the hippocampus-PCC circuit additionally contributes to Alzheimer's disease progression. Regarding functional changes, PCC is a key region of the posterior default mode network $(\mathrm{DMN})$, in which high connectivity with ventral DMN including the hippocampus region was associated with amyloid accumulation and symptom severity in sporadic Alzheimer's disease [55]. One study showed disrupted FC between the hippocampus and PCC in the early dementia stage, while not in the MCI stage [70]. Another study in PS1 mutation carriers showed decreased FC between the hippocampus and PCC in PMC, but no change in SMC [71]. Such discrepancy might be due to different population, age range, and stages in the disease spectrum. Our result of no change in the FC of the hippocampus-PCC tract with disease progression might indicate a nonlinear pattern or that the subjects were in relatively early stage of the disease progression.

For the neuropsychological and clinical correlations of the representative neural circuits, our findings suggest that all the key nodes and structural connectivity (especially axonal integrity) of both frontostrial and hippocampusPCC circuits are involved in general cognitive function and disease severity in FAD, and the presymptomatic involvement of the frontostriatal circuit structure in general cognitive function is disrupted in APP mutation carriers. 
Frontostriatal circuit functional connectivity is further involved in general cognitive function. Functional imaging studies have found that frontostriatal regions are involved in executive function and working memory [28-33], and hippocampus-PCC regions are involved in episodic memory $[34,35,72]$. Our findings indicate that not only the function, but also the structure (axonal integrity) of these circuits is involved in general cognitive function and disease severity in FAD.

This study has several limitations. First, the sample size for DTI data was relatively small, which hindered our exploration of the effect of disease progression on the neural circuits; second, the neuropsychological and clinical evaluations tested general cognition, and thus were not specific to each cognitive function domain such as episodic memory or executive function, which might be directly associated with the neural circuits in our study; third, Bonferroni correction was used for group comparisons but not for cognitive/clinical correlations, raising the possibility of a type 1 error, and the trend level results should be preliminary and exploratory (Fig. 7). However, there are fewer studies investigating white matter neural circuits than gray matter in FAD; thus, it remains helpful to search for possible useful circuit biomarkers that future studies can replicate; fourth, the DTI measurements especially FA and MD are nonspecific and only represent the general white matter integrity, though previous studies have linked early increased FA and low MD to inflammation, microglial activation/accumulation, and swelling of neurons and glia [20]. Further histology studies are needed to specify the nature of these measurements; fifth, cardiac or respiration rates were not recorded during the scanning. Although the preprocessing steps of rsfMRI can reduce the effect of them to some extent, they may still have an influence on the FC results as reported by a study [73].

\section{Conclusions}

$A P P$ and $P S 1$ gene mutations affect the frontostriatal neural circuit in a different manner, where $A P P$ primarily impairs the myelin integrity. The structure (especially axonal integrity) of the hippocampus-PCC circuit is a potential biomarker for disease progression in FAD. The structural connectivity of both frontostriatal and hippocampus-PCC circuits are associated with general cognitive function. Future studies will use a longitudinal design to evaluate the gene-specific effect and disease progression on the structure and function of the representative neural circuits, and to further link circuit imaging biomarkers with cognitive function domains.

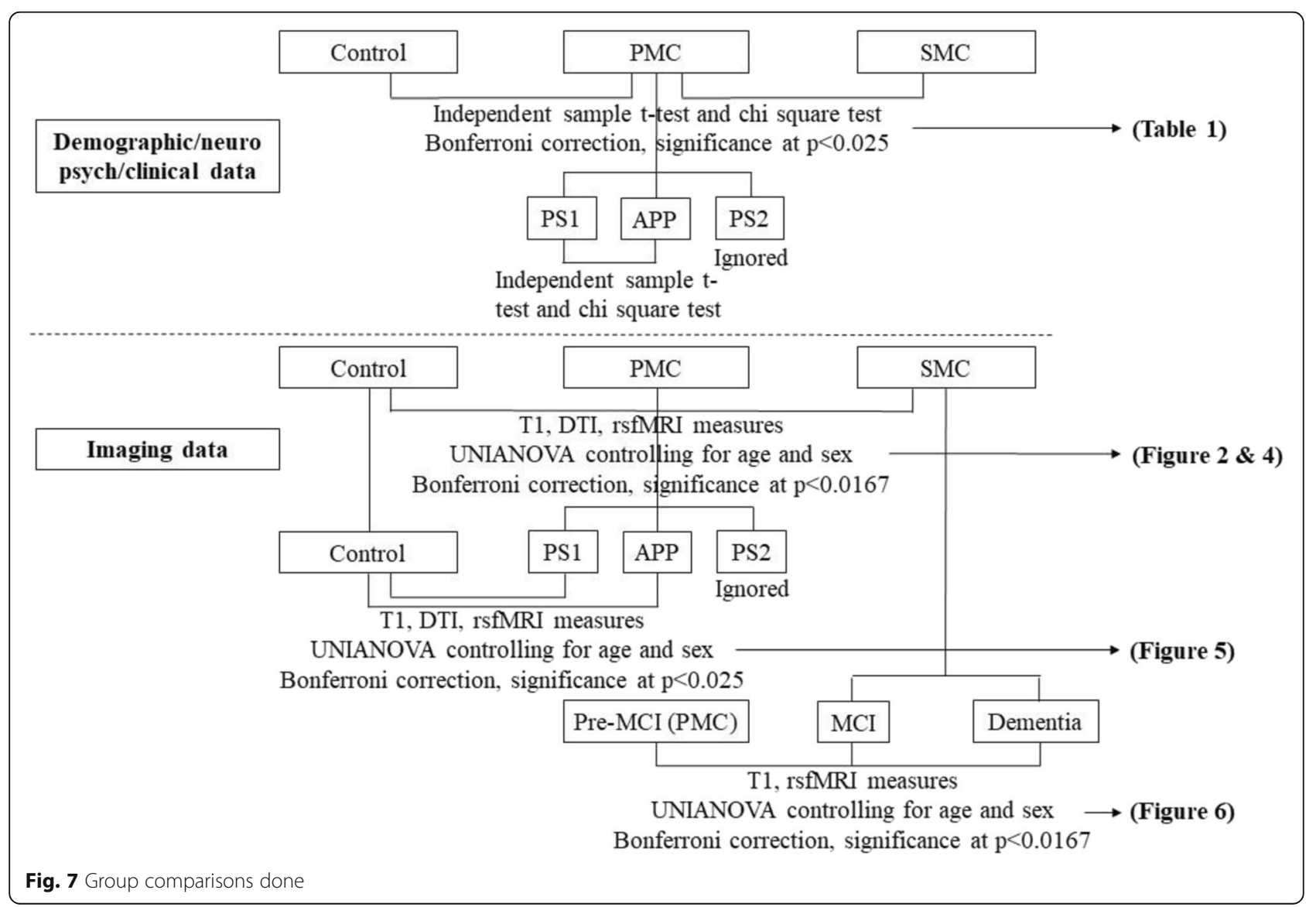




\section{Supplementary information}

The online version of this article (https://doi.org/10.1186/s13195-019-0572-2) contains supplementary material, which is available to authorized users.

Additional file 1 : Flowchart S1. Image exclusion steps. Figure S1. The ROls of a representative subject in standard space. Figure S2. Neuropsychological and clinical correlations of the structural and functional connectivity of neural circuits. Figure S3. Correlations of the $\mathrm{ROI}$ volume with MMSE. Figure S4. Correlations of the ROI volume with MoCA. Figure S5. Correlations of the ROI volume with CDR.

\section{Abbreviations}

ADAD: Autosomal dominant Alzheimer's disease; APOE: Apolipoprotein E: APP: Amyloid precursor protein; AxD: Axial diffusivity; CDR: Clinical Dementia Rating scale; DTI: Diffusion tensor imaging; EYO: Estimated years from symptom onset; FA: Fractional anisotropy; FAD: Familial Alzheimer's disease; FC: Functional connectivity; MD: Mean diffusivity; MMSE: Mini-Mental State Examination; MoCA: Montreal Cognitive Assessment; PCC: Posterior cingulate cortex; PMC: Presymptomatic mutation carrier; PS 1: Presenilin 1; PS2: Presenilin 2; RD: Radial diffusivity; rMFG: Rostral middle frontal gyrus; ROI: Region of interest; rsfMRI: Resting-state functional MRl;

SMC: Symptomatic mutation carrier

\section{Acknowledgements}

We would like to thank all the researchers in the CFAN study (http://www. chinacfan.org). We thank the participants and their families for their generous support of this study, and our clinical colleagues across China for referring patients.

\section{Authors' contributions}

MQ and JJ initiated, designed, and supervised the study; MQ and TZ performed the image quality control, preprocessing, and postprocessing; $M Q$ did the data analysis and wrote the manuscript; PL and JF acquired the imaging data from the scanner and were responsible for the scanning parameters and image acquisition part in the "Methods" section; TZ, YT, WW, $\mathrm{QQ}, \mathrm{TL}, \mathrm{QW}$, and JJ gave some comments and participated in the discussion for this manuscript. All authors read and approved the final manuscript.

\section{Funding}

This study was supported by the research grants to MQ from Beijing Postdoctoral Research Foundation and research grants to JJ from the National Natural Science Foundation of China for the Key Project (81530036), the National Key Scientific Instrument and Equipment Development Project (31627803), Beijing Municipal Administration of Hospitals for Mission Program (SML20150801), Beijing Municipal Human Resources and Social Security Bureau for the Beijing Scholars Program, Beijing Municipal Science \& Technology Commission for the Beijing Brain Initiative (Z161100000216137), and Beijing Municipal Commission of Health and Family Planning (PXM2018_026283_000002).

\section{Availability of data and materials}

Both raw and processed data that support the findings of the current study will be made available upon request to the corresponding author and the CFAN committee in order to ensure that the privacy of the CFAN participants is protected.

\section{Ethics approval and consent to participate}

Written informed consents were obtained from all the participants before undergoing any procedure. Approvals were obtained from the Medical Research Ethics Committee at Xuanwu Hospital before that participants underwent any procedures.

\section{Consent for publication}

Not applicable.

\section{Competing interests}

The authors declare that they have no competing interests.

\section{Author details}

Innovation Center for Neurological Disorders and Department of Neurology, Xuanwu Hospital, Capital Medical University, National Clinical Research Center for Geriatric Diseases, Beijing, People's Republic of China. ${ }^{2}$ Beijing Key Laboratory of Geriatric Cognitive Disorders, Beijing, People's Republic of China. ${ }^{3}$ Clinical Center for Neurodegenerative Disease and Memory Impairment, Capital Medical University, Beijing, People's Republic of China. ${ }^{4}$ Center of Alzheimer's Disease, Beijing Institute for Brain Disorders, Beijing, People's Republic of China. ${ }^{5}$ Guang'anmen Hospital, China Academy of Chinese Medical Sciences, Beijing, China.

Received: 23 September 2019 Accepted: 23 December 2019

Published online: 14 January 2020

\section{References}

1. Collaborators GBDD. Global, regional, and national burden of Alzheimer's disease and other dementias, 1990-2016: a systematic analysis for the Global Burden of Disease Study 2016. Lancet Neurol. 2019;181:88-106.

2. Jia L, Quan M, Fu Y, Zhao T, Li Y, Wei C, Tang Y, Qin Q, Wang F, Qiao Y, et al. Dementia in China: epidemiology, clinical management, and research advances. Lancet Neurol. 2019; https://doi.org/10.1016/S14744422(19)30290-X.

3. Knopman DS. Lowering of amyloid-beta by beta-secretase inhibitors - some informative failures. N Engl J Med. 2019;38015:1476-8.

4. Canter RG, Penney J, Tsai LH. The road to restoring neural circuits for the treatment of Alzheimer's disease. Nature. 2016;5397628:187-96.

5. Laxton AW, Tang-Wai DF, McAndrews MP, Zumsteg D, Wennberg R, Keren R, Wherrett J, Naglie G, Hamani C, Smith GS, et al. A phase I trial of deep brain stimulation of memory circuits in Alzheimer's disease. Ann Neurol. 2010;684:521-34.

6. Kuhn J, Hardenacke K, Shubina E, Lenartz D, Visser-Vandewalle V, Zilles K, Sturm $V$, Freund HJ. Deep brain stimulation of the nucleus basalis of Meynert in early stage of Alzheimer's dementia. Brain Stimul. 2015;84:838-9.

7. Deeb W, Salvato B, Almeida L, Foote KD, Amaral R, Germann J, Rosenberg PB, Tang-Wai DF, Wolk DA, Burke AD, et al. Fornix-region deep brain stimulation-induced memory flashbacks in Alzheimer's disease. N Engl J Med. 2019:3818:783-5.

8. Goldman JS, Hahn SE, Catania JW, LaRusse-Eckert S, Butson MB, Rumbaugh M, Strecker MN, Roberts JS, Burke W, Mayeux R, et al. Genetic counseling and testing for Alzheimer disease: joint practice guidelines of the American College of Medical Genetics and the National Society of Genetic Counselors. Genet Med. 2011:136:597-605.

9. Jia L, Fu Y, Shen L, Zhang H, Zhu M, Qiu Q, Wang Q, Yan X, Kong C, Hao J, et al. PSEN1, PSEN2 and APP mutations in 404 Chinese pedigrees with familial Alzheimer's disease. Alzheimers Dement. 2019; https://doi.org/10. 1002/alz.12005

10. Reiman EM, Langbaum JB, Tariot PN, Lopera F, Bateman RJ, Morris JC, Sperling RA, Aisen PS, Roses AD, Welsh-Bohmer KA, et al. CAP--advancing the evaluation of preclinical Alzheimer disease treatments. Nat Rev Neurol. 2016:121:56-61.

11. Tariot PN, Lopera F, Langbaum JB, Thomas RG, Hendrix S, Schneider LS, Rios-Romenets S, Giraldo M, Acosta N, Tobon C, et al. The Alzheimer's Prevention Initiative Autosomal-Dominant Alzheimer's Disease Trial: A study of crenezumab versus placebo in preclinical PSEN1 E280A mutation carriers to evaluate efficacy and safety in the treatment of autosomal-dominant Alzheimer's disease, including a placebo-treated noncarrier cohort. Alzheimers Dement (N Y). 2018;4:150-60.

12. Klunk WE, Price JC, Mathis CA, Tsopelas ND, Lopresti BJ, Ziolko SK, Bi W, Hoge JA, Cohen AD, Ikonomovic MD, et al. Amyloid deposition begins in the striatum of presenilin-1 mutation carriers from two unrelated pedigrees. J Neurosci. 2007:2723:6174-84

13. Villemagne $V L$, Ataka S, Mizuno T, Brooks WS, Wada Y, Kondo M, Jones G, Watanabe $Y$, Mulligan $R$, Nakagawa M, et al. High striatal amyloid betapeptide deposition across different autosomal Alzheimer disease mutation types. Arch Neurol. 2009;6612:1537-44.

14. Cohen AD, McDade E, Christian B, Price J, Mathis C, Klunk W, Handen BL. Early striatal amyloid deposition distinguishes Down syndrome and autosomal dominant Alzheimer's disease from late-onset amyloid deposition. Alzheimers Dement. 2018;146:743-50.

15. Gordon BA, Blazey TM, Su Y, Hari-Raj A, Dincer A, Flores S, Christensen J, McDade E, Wang G, Xiong C, et al. Spatial patterns of neuroimaging 
biomarker change in individuals from families with autosomal dominant Alzheimer's disease: a longitudinal study. Lancet Neurol. 2018;173:241-50.

16. Bateman RJ, Xiong C, Benzinger TL, Fagan AM, Goate A, Fox NC, Marcus DS, Cairns NJ, Xie X, Blazey TM, et al. Clinical and biomarker changes in dominantly inherited Alzheimer's disease. N Engl J Med. 2012;3679:795-804.

17. Hanseeuw BJ, Lopera F, Sperling RA, Norton DJ, Guzman-Velez E, Baena A, Pardilla-Delgado E, Schultz AP, Gatchel J, Jin D, et al. Striatal amyloid is associated with tauopathy and memory decline in familial Alzheimer's disease. Alzheimers Res Ther. 2019;111:17.

18. Benzinger TL, Blazey T, Jack CR Jr, Koeppe RA, Su Y, Xiong C, Raichle ME, Snyder AZ, Ances BM, Bateman RJ, et al. Regional variability of imaging biomarkers in autosomal dominant Alzheimer's disease. Proc Natl Acad Sci U S A. 2013;11047:E4502-9.

19. Lee GJ, Lu PH, Medina LD, Rodriguez-Agudelo Y, Melchor S, Coppola G, Braskie MN, Hua X, Apostolova LG, Leow AD, et al. Regional brain volume differences in symptomatic and presymptomatic carriers of familial Alzheimer's disease mutations. J Neurol Neurosurg Psychiatry. 2013;842:154-62.

20. Ryan NS, Keihaninejad S, Shakespeare TJ, Lehmann M, Crutch SJ, Malone IB,

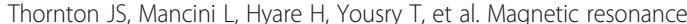
imaging evidence for presymptomatic change in thalamus and caudate in familial Alzheimer's disease. Brain. 2013;136Pt 5:1399-414.

21. Wang G, Coble D, McDade EM, Hassenstab J, Fagan AM, Benzinger TLS, Bateman RJ, Morris JC, Xiong C, Dominantly Inherited Alzheimer N. Staging biomarkers in preclinical autosomal dominant Alzheimer's disease by estimated years to symptom onset. Alzheimers Dement. 2019;154:506-14.

22. Jack CR Jr, Barkhof F, Bernstein MA, Cantillon M, Cole PE, Decarli C, Dubois B, Duchesne S, Fox NC, Frisoni GB, et al. Steps to standardization and validation of hippocampal volumetry as a biomarker in clinical trials and diagnostic criterion for Alzheimer's disease. Alzheimers Dement. 2011;74: 474-85. e4

23. Fortea J, Sala-Llonch R, Bartres-Faz D, Bosch B, Llado A, Bargallo N, Molinuevo JL, Sanchez-Valle R. Increased cortical thickness and caudate volume precede atrophy in PSEN1 mutation carriers. J Alzheimers Dis. 2010; 223:909-22.

24. Quiroz YT, Budson AE, Celone K, Ruiz A, Newmark R, Castrillon G, Lopera F, Stern CE. Hippocampal hyperactivation in presymptomatic familial Alzheimer's disease. Ann Neurol. 2010;686:865-75.

25. Braskie MN, Medina LD, Rodriguez-Agudelo Y, Geschwind DH, Macias-Islas MA, Thompson PM, Cummings JL, Bookheimer SY, Ringman JM. Memory performance and fMRI signal in presymptomatic familial Alzheimer's disease. Hum Brain Mapp. 2013;3412:3308-19.

26. McDade E, Kim A, James J, Sheu LK, Kuan DC, Minhas D, Gianaros PJ, Ikonomovic S, Lopez O, Snitz B, et al. Cerebral perfusion alterations and cerebral amyloid in autosomal dominant Alzheimer disease. Neurology. 2014:838:710-7.

27. Lanciego JL, Luquin N, Obeso JA. Functional neuroanatomy of the basal ganglia. Cold Spring Harb Perspect Med. 2012;212:a009621.

28. Alexander GE, DeLong MR, Strick PL. Parallel organization of functionally segregated circuits linking basal ganglia and cortex. Annu Rev Neurosci. 1986:9:357-81

29. Parent A, Hazrati LN. Functional anatomy of the basal ganglia. I. the corticobasal ganglia-thalamo-cortical loop. Brain Res Brain Res Rev. 1995;201:91-127.

30. Draganski B, Kherif F, Kloppel S, Cook PA, Alexander DC, Parker GJ, Deichmann R, Ashburner J, Frackowiak RS. Evidence for segregated and integrative connectivity patterns in the human basal ganglia. J Neurosci. 2008;2828:7143-52.

31. Quan M, Lee SH, Kubicki M, Kikinis Z, Rathi Y, Seidman LJ, MesholamGately RI, Goldstein JM, McCarley RW, Shenton ME, et al. White matter tract abnormalities between rostral middle frontal gyrus, inferior frontal gyrus and striatum in first-episode schizophrenia. Schizophr Res. 2013; 1451-3:1-10.

32. Vaghi MM, Vertes PE, Kitzbichler MG, Apergis-Schoute AM, van der Flier FE, Fineberg NA, Sule A, Zaman R, Voon V, Kundu P, et al. Specific frontostriatal circuits for impaired cognitive flexibility and goal-directed planning in obsessive-compulsive disorder: evidence from resting-state functional connectivity. Biol Psychiatry. 2017;818:708-17.

33. Salmi J, Nyberg L, Laine M. Working memory training mostly engages general-purpose large-scale networks for learning. Neurosci Biobehav Rev. 2018;93:108-22.

34. Papma JM, Smits M, de Groot M, Mattace Raso FU, van der Lugt A, Vrooman HA, Niessen WJ, Koudstaal PJ, van Swieten JC, van der Veen FM, et al. The effect of hippocampal function, volume and connectivity on posterior cingulate cortex functioning during episodic memory fMRI in mild cognitive impairment. Eur Radiol. 2017;279:3716-24.

35. Grothe MJ, Heinsen H, Amaro E Jr, Grinberg LT, Teipel SJ. Cognitive correlates of basal forebrain atrophy and associated cortical Hypometabolism in mild cognitive impairment. Cereb Cortex. 2016;266:2411-26.

36. Guzman-Velez E, Jaimes S, Aguirre-Acevedo DC, Norton DJ, Papp KV, Amariglio R, Rentz D, Baena A, Henao E, Tirado V, et al. A three-factor structure of cognitive functioning among unimpaired carriers and non-carriers of autosomal-dominant Alzheimer's disease. J Alzheimers Dis. 2018;651:107-15.

37. Ihara R, Iwata A, Suzuki K, Ikeuchi T, Kuwano R, Iwatsubo T, Japanese Alzheimer's Disease Neuroimaging I. Clinical and cognitive characteristics of preclinical Alzheimer's disease in the Japanese Alzheimer's Disease Neuroimaging Initiative cohort. Alzheimers Dement (N Y). 2018;4:645-51.

38. Scahill Rl, Ridgway GR, Bartlett JW, Barnes J, Ryan NS, Mead S, Beck J, Clarkson MJ, Crutch SJ, Schott JM, et al. Genetic influences on atrophy patterns in familial Alzheimer's disease: a comparison of APP and PSEN1 mutations. J Alzheimers Dis. 2013;351:199-212.

39. Tentolouris-Piperas V, Ryan NS, Thomas DL, Kinnunen KM. Brain imaging evidence of early involvement of subcortical regions in familial and sporadic Alzheimer's disease. Brain Res. 2017;1655:23-32.

40. Chiesa PA, Cavedo E, Lista S, Thompson PM, Hampel H, Alzheimer precision medicine I. Revolution of resting-state functional neuroimaging genetics in Alzheimer's disease. Trends Neurosci. 2017;408:469-80.

41. Fischl B, Salat DH, Busa E, Albert M, Dieterich M, Haselgrove C, van der Kouwe A, Killiany R, Kennedy D, Klaveness S, et al. Whole brain segmentation: automated labeling of neuroanatomical structures in the human brain. Neuron. 2002;333:341-55.

42. Kikinis Z, Fallon JH, Niznikiewicz M, Nestor P, Davidson C, Bobrow L, Pelavin PE, Fischl B, Yendiki A, McCarley RW, et al. Gray matter volume reduction in rostral middle frontal gyrus in patients with chronic schizophrenia. Schizophr Res. 2010;1232-3:153-9.

43. Behrens TE, Berg HJ, Jbabdi S, Rushworth MF, Woolrich MW. Probabilistic diffusion tractography with multiple fibre orientations: what can we gain? Neuroimage. 2007;341:144-55.

44. Greve DN, Fischl B. Accurate and robust brain image alignment using boundary-based registration. Neuroimage. 2009;481:63-72.

45. Ashburner J. SPM: a history. Neuroimage. 2012;622:791-800.

46. Xu K, Liu Y, Zhan Y, Ren J, Jiang T. BRANT: a versatile and extendable resting-state fMRI toolkit. Front Neuroinform. 2018:12:52.

47. Quiroz YT, Schultz AP, Chen K, Protas HD, Brickhouse M, Fleisher AS, Langbaum JB, Thiyyagura P, Fagan AM, Shah AR, et al. Brain imaging and blood biomarker abnormalities in children with autosomal dominant Alzheimer disease: a cross-sectional study. JAMA Neurol. 2015;728:912-9.

48. Tang Y, Xing Y, Zhu Z, He Y, Li F, Yang J, Liu Q, Li F, Teipel SJ, Zhao G, et al. The effects of 7-week cognitive training in patients with vascular cognitive impairment, no dementia (the cog-VACCINE study): a randomized controlled trial. Alzheimers Dement. 2019;155:605-14

49. Lim HK, Nebes R, Snitz B, Cohen A, Mathis C, Price J, Weissfeld L, Klunk W, Aizenstein $\mathrm{HJ}$. Regional amyloid burden and intrinsic connectivity networks in cognitively normal elderly subjects. Brain. 2014;137Pt 12:3327-38.

50. Fleisher AS, Chen K, Quiroz YT, Jakimovich LJ, Gutierrez Gomez M, Langois CM, Langbaum JB, Roontiva A, Thiyyagura P, Lee W, et al. Associations between biomarkers and age in the presenilin 1 E280A autosomal dominant Alzheimer disease kindred: a cross-sectional study. JAMA Neurol. 2015;723:316-24.

51. Sala-Llonch R, Llado A, Fortea J, Bosch B, Antonell A, Balasa M, Bargallo N Bartres-Faz D, Molinuevo JL, Sanchez-Valle R. Evolving brain structural changes in PSEN1 mutation carriers. Neurobiol Aging. 2015;363:1261-70.

52. Araque Caballero MA, Suarez-Calvet $M$, Duering $M$, Franzmeier $N$, Benzinger T, Fagan AM, Bateman RJ, Jack CR, Levin J, Dichgans M, et al. White matter diffusion alterations precede symptom onset in autosomal dominant Alzheimer's disease. Brain. 2018;14110:3065-80.

53. Zheng K, Wang H, Li J, Yan B, Liu J, Xi Y, Zhang X, Yin H, Tan Q, Lu H, et al. Structural networks analysis for depression combined with graph theory and the properties of fiber tracts via diffusion tensor imaging. Neurosci Lett. 2019;694:34-40.

54. Kuchtova B, Wurst Z, Mrzilkova J, Ibrahim I, Tintera J, Bartos A, Musil V, Kieslich K, Zach P. Compensatory shift of subcallosal area and paraterminal gyrus white matter parameters on DTI in patients with Alzheimer disease. Curr Alzheimer Res. 2018;156:590-9. 
55. Jones DT, Knopman DS, Gunter JL, Graff-Radford J, Vemuri P, Boeve BF, Petersen RC, Weiner MW, Jack CR Jr, Alzheimer's Disease Neuroimaging I. Cascading network failure across the Alzheimer's disease spectrum. Brain. 2016;139Pt 2:547-62.

56. Grothe MJ, Teipel SJ, Alzheimer's Disease neuroimaging I. spatial patterns of atrophy, hypometabolism, and amyloid deposition in Alzheimer's disease correspond to dissociable functional brain networks. Hum Brain Mapp. 2016; 371:35-53.

57. Myers N, Pasquini L, Gottler J, Grimmer T, Koch K, Ortner M, Neitzel J, Muhlau M, Forster S, Kurz A, et al. Within-patient correspondence of amyloid-beta and intrinsic network connectivity in Alzheimer's disease Brain. 2014;137Pt 7:2052-64.

58. Weiner MW, Veitch DP, Aisen PS, Beckett LA, Cairns NJ, Green RC, Harvey D, Jack CR Jr, Jagust W, Morris JC, et al. Recent publications from the Alzheimer's disease neuroimaging initiative: reviewing progress toward improved AD clinical trials. Alzheimers Dement. 2017;134:e1-e85.

59. Ringman JM, O'Neill J, Geschwind D, Medina L, Apostolova LG, Rodriguez Y Schaffer B, Varpetian A, Tseng B, Ortiz F, et al. Diffusion tensor imaging in preclinical and presymptomatic carriers of familial Alzheimer's disease mutations. Brain. 2007;130Pt 7:1767-76.

60. Song SK, Sun SW, Ju WK, Lin SJ, Cross AH, Neufeld AH. Diffusion tensor imaging detects and differentiates axon and myelin degeneration in mouse optic nerve after retinal ischemia. Neuroimage. 2003;203:1714-22.

61. lacono D, Markesbery WR, Gross M, Pletnikova O, Rudow G, Zandi P, Troncoso JC. The Nun study: clinically silent AD, neuronal hypertrophy, and linguistic skills in early life. Neurology. 2009;739:665-73.

62. Cai S, Peng Y, Chong T, Zhang Y, von Deneen KM, Huang L, Alzheimer's Disease Neuroimaging I. Differentiated effective connectivity patterns of the executive control network in progressive $\mathrm{MCl}$ : a potential biomarker for predicting AD. Curr Alzheimer Res. 2017;149:937-50.

63. Karch CM, Goate AM. Alzheimer's disease risk genes and mechanisms of disease pathogenesis. Biol Psychiatry. 2015;771:43-51.

64. van der Kant R, Goldstein LS. Cellular functions of the amyloid precursor protein from development to dementia. Dev Cell. 2015;324:502-15.

65. Hung COY, Livesey FJ. Altered gamma-secretase processing of APP disrupts lysosome and autophagosome function in monogenic Alzheimer's disease. Cell Rep. 2018;2513:3647-60. e2

66. Duggan SP, McCarthy JV. Beyond gamma-secretase activity: the multifunctional nature of presenilins in cell signalling pathways. Cell Signal. 2016;281:1-11

67. Ridha BH, Barnes J, Bartlett JW, Godbolt A, Pepple T, Rossor MN, Fox NC. Tracking atrophy progression in familial Alzheimer's disease: a serial MRI study. Lancet Neurol. 2006;510:828-34.

68. Jacobs HIL, Hedden T, Schultz AP, Sepulcre J, Perea RD, Amariglio RE, Papp $\mathrm{KV}$, Rentz DM, Sperling RA, Johnson KA. Structural tract alterations predict downstream tau accumulation in amyloid-positive older individuals. Nat Neurosci. 2018;213:424-31.

69. Lee SH, Coutu JP, Wilkens P, Yendiki A, Rosas HD, Salat DH, Alzheimer's disease Neuroimaging I. Tract-based analysis of white matter degeneration in Alzheimer's disease. Neuroscience. 2015;301:79-89.

70. Zhou Y, Dougherty JH Jr, Hubner KF, Bai B, Cannon RL, Hutson RK. Abnormal connectivity in the posterior cingulate and hippocampus in early Alzheimer's disease and mild cognitive impairment. Alzheimers Dement. 2008:44:265-70.

71. Sala-Llonch R, Fortea J, Bartres-Faz D, Bosch B, Llado A, Pena-Gomez C, Antonell A, Castellanos-Pinedo F, Bargallo N, Molinuevo JL, et al. Evolving brain functional abnormalities in PSEN1 mutation carriers: a resting and visual encoding fMRI study. J Alzheimers Dis. 2013;361:165-75.

72. Reiman EM, Quiroz YT, Fleisher AS, Chen K, Velez-Pardo C, Jimenez-Del-Rio M, Fagan AM, Shah AR, Alvarez S, Arbelaez A, et al. Brain imaging and fluid biomarker analysis in young adults at genetic risk for autosomal dominant Alzheimer's disease in the presenilin 1 E280A kindred: a case-control study. Lancet Neurol. 2012;1112:1048-56.

73. Chang C, Metzger CD, Glover GH, Duyn JH, Heinze HJ, Walter M. Association between heart rate variability and fluctuations in resting-state functional connectivity. Neuroimage. 2013;68:93-104.

\section{Publisher's Note}

Springer Nature remains neutral with regard to jurisdictional claims in published maps and institutional affiliations.

\section{Ready to submit your research? Choose BMC and benefit from}

- fast, convenient online submission

- thorough peer review by experienced researchers in your field

- rapid publication on acceptance

- support for research data, including large and complex data types

- gold Open Access which fosters wider collaboration and increased citations

- maximum visibility for your research: over $100 \mathrm{M}$ website views per year

At $\mathrm{BMC}$, research is always in progress.

Learn more biomedcentral.com/submissions 